\title{
An empirical evaluation of three post-Keynesian models
}

\author{
Peter Skott* and Ben Zipperer*
}

\begin{abstract}
Structuralist and post-Keynesian models differ in their assumptions about firms' investment behavior and pricingloutput decisions. This paper compares three benchmark models: Kaleckian, Robinsonian and Kaldorian. We analyze the implications of these models for the steady growth path and the cyclical properties of the economy, and evaluate the consistency of the theoretical predictions with empirical evidence for the US. Our regression results and the stylized cyclical pattern of key variables are consistent with the Kaldorian model. The Kaleckian investment function and the Robinsonian pricing behavior find no support in the data.

JEL classifications: EI2, E32, $O_{4 I}$

Keywords: growth, business cycles, aggregate demand, instability, income distribution, utilization rate, investment function, pricing
\end{abstract}

\section{Introduction}

The irrelevance of much of contemporary macroeconomics for an understanding of the severe recession that started in 2008 has given new credibility to traditional Keynesian short-run analysis. The majority view, however, rejects the use of Keynesian theory for the medium

* Department of Economics, University of Massachusetts Amherst, MA oıоo3, USA. Early versions of this paper have been presented at the $\mathrm{I}^{\text {th }}$ Conference of the Research Network on Macroeconomics, Berlin 2009, the Analytical Political Economy Workshop, Queen Mary University London 20Io, the Eastern Economic Association Meetings 20Io, and at seminars at the University of Massachusetts and Hamburg University. We thank the participants and two anonymous referees of this journal for helpful comments and suggestions.

Correspondence Address:

Peter Skott, Department of Economics, University of Massachusetts Amherst, MA огоо3, USA, e-mail: pskott@econs.umass.edu.

Received 20 December 20II, accepted I April 2012

(C) INTERVENTION 9 (2), 20I2, 277-308 
and long run. We believe this rejection is unfounded, but Keynesian ideas come in many varieties, and an attempt should be made to resolve fundamental disagreements within the (post-)Keynesian and structuralist traditions. This paper compares three different models: Kaleckian, Robinsonian and Kaldorian. We outline the main theoretical assumptions and implications, and use US data to evaluate the models empirically. ${ }^{\mathrm{I}}$

The Kaleckian tradition, in our definition, is distinguished from the other two by the use of the utilization rate of capital as an accommodating variable: A permanent shift in saving behavior or a change in animal spirits can lead to a large, permanent change in the utilization rate. The Robinsonian and Kaldorian models by contrast, take the desired utilization rate as structurally determined. Desired utilization is largely independent of shocks to aggregate demand, and the models exclude persistent deviations of actual from desired utilization. Actual utilization may fluctuate around the desired rate, but scenarios in which the actual rate stays permanently above (or below) the desired rate are ruled out.

Robinsonian and Kaldorian models share another property: both traditions include endogenous changes in income distribution as a crucial element. They differ, however, in the detailed specification of firms' behavior and in the mechanism that generates consistency between long-run average utilization rates and desired rates. The Robinsonian model sees income distribution as the variable that responds to discrepancies between actual and desired utilization; Kaldorian models rely on adjustments in capital accumulation. These behavioral responses away from steady growth can generate endogenous fluctuations around a locally asymptotically unstable growth path in both Robinsonian and Kaldorian models, but the predicted cyclical patterns are different. Kaleckian models typically focus on the determination of the steady-growth solution, but a stable short-run dynamics can be added to the standard specification and cycles can arise in these models, too.

All the models in this paper may seem unusual in one respect. Post-Keynesian models often leave out labor markets and labor constraints on the rate of growth. This can be appropriate for dual economies with significant amounts of hidden or open unemployment, but our empirical evidence relates to the US economy, and the theoretical analysis therefore focuses on labor-constrained models. There are both theoretical and empirical reasons for using US data as the testing ground. The models describe pure capitalist economies; they are typically cast in terms of closed economies without a public sector, and a one-good assumption implies that sectoral differences are taken to be insignificant. The US is as close as one gets to a closed economy, the size of the public sector is relatively modest, and unlike Japan and many European economies, the US did not have large amounts of hidden unemployment in backward sectors for a good part of the post-war period. With respect to data, moreover, quarterly series are available for some of the key variables in heterodox models.

The rest of this paper is divided into three sections. Section 2 presents the theoretical models and their implications. We first outline, in Section 2.I, a common framework for

I The delineation of different approaches may be contentious and our benchmark models clearly do not do justice to the rich analysis in the writings of Kalecki, Robinson, Kaldor and the subsequent traditions. 
the analysis of steady growth in a mature economy, and then, in Sections 2.2-2.4, derive the steady growth solutions and short-run dynamics of our three benchmark models. Section 3 evaluates the models. US trends and cycles of the key variables are described and compared to the predicted cyclical patterns in Section 3.I; Section 3.2 contains regression results for the investment and pricing/output functions. Section 4 summarizes the main conclusions.

\section{Three benchmark models of a mature economy}

The focus on mature economies calls for two observations. Maturity, first, does not imply full employment. The key property of a mature economy is the importance of the unemployment rate as a meaningful variable whose value influences at least one of the proximate determinants of the growth rate (firms' accumulation and pricing/output decisions, and the saving rate). Not all economies are mature in this sense. The measured unemployment rate has been irrelevant for the determination of the growth rate of the Chinese economy: Large reserves of hidden unemployment means that, so far, labor constraints have had little or no influence on the ability of the modern sector to expand output and employment. The same argument applies to Japan during its years of miracle growth and to many European countries until some time in the post-war period. The US, Japanese, and most European economies are now mature, however, and the unemployment rate has become an important indicator. These economies may not have full employment, but the long-run growth rate is constrained by the growth rate of the labor force, and the growth rate of the labor force is not perfectly elastic.

The second observation is that maturity does not exclude long-run effects of aggregate demand. If the growth rate of the labor force is taken to be exogenous, the long-run effects are level effects on the rate of employment, rather than growth effects. But the growth rate of the labor force need not be exogenous in a mature economy. Labor-constrained models are consistent with the endogenous determination of the growth of the labor force, and the rate of employment may be one of the determinants of the growth rate. Induced migration is an obvious mechanism in open economies; for a closed economy, changes in participation rates may affect the growth of the labor force in the medium run, and high employment and incipient labor shortages may serve as incentives for labor saving innovation in the long run. This potential endogeneity of the effective labor force is largely orthogonal to disagreements on the determination of firms' investment and pricing/output decisions. Moreover, there is no general consensus on the determination of the growth of the effective labor. Most of our theoretical analysis therefore takes the growth rate of the labor force as an exogenous constant. In a couple of places, however, we shall comment on the implications of having the growth of the effective labor force $n$ as an increasing function of the employment rate $e: n=n(e), n^{\prime}(e) \geq 0 .^{2}$

2 This specification has been used by Flaschel/Skott (2006); Bhaduri (2003) and Dutt (2006) discuss induced technical progress along similar lines. 


\section{I Steady growth in a mature economy - a common framework}

To simplify, it is assumed that the production function has fixed coefficients and that there are only two inputs, capital and labor. ${ }^{3}$ Algebraically,

$$
Y=\min \{L, \sigma K\},
$$

where $L$ is employment and where the labor unit has been chosen so as to give a (minimum) labor-output ratio of one. Labor hoarding plays no role in any of the three approaches, and we assume that

$$
L=Y .
$$

The firm is left with two sets of decisions, an investment decision and a pricing/output decision. The decision problem is complex, but the steady-growth implications of the decisions can be described by two equations:

$$
\begin{aligned}
& g=\phi(u, \pi, e), \quad \phi_{u} \geq 0, \phi_{\pi} \geq 0, \phi_{e} \leq 0, \\
& \pi=\xi(e, g, u), \quad \xi_{e} \geq 0, \xi_{g} \geq 0,
\end{aligned}
$$

where $g, u, \pi$ and $e$ are the rate of (net) accumulation (which is equal to the growth rate of output in steady growth), the rate of utilization, the share of profits and the employment rate, respectively. A fixed coefficient production function implies that the utilization rate is well-defined, and we use the output-capital ratio as a measure of the utilization rate: $u=Y / K$. It also implies that marginal cost (equal to average variable cost) is equal to unit wage cost and that there is a simple relation between the profit share and the markup on wage cost: $\pi=m /(1+m)$, where $m$ is the markup on unit wage cost.

In equation (3), the influence of utilization and the profit share on accumulation is standard, and traditional Marxian and Kaleckian insights suggest a negative employment effect: A sustained increase in employment strengthens workers vis-a-vis management, and animal spirits may suffer as a result. ${ }^{4}$

The pricing equation (4) also includes the employment rate. This can be justified by monopsony effects - an effect of aggregate employment on the perceived elasticity of labor supply to the individual firm - which make the profit-maximizing profit share an increasing function of the employment rate..$^{5}$ From a Neo-Marxian perspective the positive relation

3 Most post-Keynesian and structuralist models pay little attention to the choice of technique; see Skott (1989a) for an exception.

4 A referee has suggested that high employment rates could increase the expected future demand and exert a positive effect on investment. In principle this mechanism could operate. We do not find it plausible, however, and our regressions in section 3 consistently show a negative effect. The negative effect is in line with Robinson's (I962) argument (cf. footnote I6 below); see also Flaschel/Skott (2006) and Ryoo/Skott (2008).

5 Manning (2003) provides an extended analysis of monopsonistic features of the labor market. 
between employment and the profit share may seem surprising: These theories sometimes suggest that an increase in employment will raise workers' bargaining power and the real wage. It is important to note, however, that equation (4) describes firms' pricing/output decisions. General Marx-Kalecki arguments suggest that these pricing/output decisions will be affected as indicated by equation (4): An increase in the employment rate produces a deterioration of the business climate and requires a higher profit share if firms are to maintain any given growth rate (analogously, for any given employment rate, an increase in profitability may be needed to induce firms to raise the growth rate).

The pricing decisions could be combined with the introduction of an upwardsloping 'wage curve based on neo-Marxian bargaining considerations. This combination, however, leads to overdetermination in a model with a Keynesian aggregate demand side. The present model may be slightly more complex, but the overdetermination arises for the same basic reasons as in Marglin (1984). Marglin's solution was to introduce inflation as an accommodating variable to resolve the overdetermination in his hybrid model. Our preferred solution focuses on the endogeneity of wage aspirations as a source of hysteresis (Skott 1999 and 2005a): If wage norms and aspirations have a conventional element - are influenced by past experience - then the wage curve will itself be shifting endogenously. Thus, the steady growth paths can be determined by the equilibrium condition for the product market in combination with the pricing/output decision.

The utilization effect on the profit share may seem less compelling (and the sign is left open), but a positive partial with respect to $u$ could be generated by aggregation. By assumption, the production function has fixed coefficients and there is excess capacity, but if firm-level demand has a random element then firm-level utilization rates will be distributed around the economy-wide average. The higher the average utilization rate, the larger the proportion of firms that comes up against their capacity limit, and the aggregate relation follows if constrained firms raise their markup.

Equations (3) - (4) define firms' investment and pricing/output decisions in steady growth. If the conditions are satisfied then, by construction, firms are willing to expand their capital and output at the growth rate $g$ and keep their markup at the value that is consistent with the profit share $\pi$. The equations have been listed with the accumulation rate and the profit share as left-hand-side variables, but they describe steady-growth conditions and can equally well be written with other dependent variables. If $\phi_{u} \neq 0$, the investment decision can be rephrased as an equation with the desired steady-growth utilization rate as a function of $g, \pi$ and $e$. Analogously, the pricing equation (4) can be rephrased with the growth rate on the left hand side if $\xi_{g} \neq 0$. Our Kaldorian model makes use of this alternative representation of equation (4).

To complete the model we specify a simple saving function, an equilibrium condition for the product market and a maturity condition:

$$
\frac{S}{K}=s u \pi,
$$




$$
\begin{aligned}
& \frac{S}{K}=\operatorname{su} \pi=g+\delta=\frac{I}{K}, \\
& g=n,
\end{aligned}
$$

where $S$ and $K$ are (real, gross) saving and the capital stock, $s$ is the saving rate out of profits, $u$ the output-capital ratio and $\pi$ the (gross) profit share; $I$ is the (real, gross) investment, $\delta$ the rate of depreciation, and $n$ the growth rate of the labor force (Harrod's natural growth rate).

The specification of the saving function in equation (5) could be relaxed; the important assumption is differential saving with a higher saving rate out of profits than out of wages. Equation (6) is the equilibrium condition for a stripped-down, closed economy without a public sector, and equation (7) represents the maturity condition. The steady growth rate cannot exceed the rate of growth of the labor force (adjusted for technical change) in a mature economy, and growth rates below the maximum level permitted by the growth of the labor force would turn the economy into a non-constrained, dual economy. Thus, the growth rate of employment must equal the growth rate of the labor force.

A steady-growth solution for $u, \pi, g$, e satisfies equations (3) - (4) and (6) - (7). Kaleckian, Robinsonian and Kaldorian models share this general framework. They differ, however, in the precise specification of the pricing/output and accumulation equations (equations $(3)-(4)$ ) as well as in the dynamics away from steady growth.

\subsection{A Kaleckian model}

\subsection{Steady growth}

The Kaleckian model has developed from the work by Rowthorn (I98I), Dutt (1984) and Marglin and Bhaduri (I990). ${ }^{6}$ The model typically employs a linear investment function which includes the utilization rate and the profit share among the explanatory variables. We adapt this formulation to a mature economy by adding the employment rate: ${ }^{7}$

$$
\frac{I}{K}=f(u, \pi, e)=\alpha_{0}+\alpha_{1} u+\alpha_{2} \pi-\alpha_{3} e .
$$

The distinctive characteristic of this Kaleckian version of equation (3) is a restriction on the value of $\alpha_{1}$ : The model imposes a `Keynesian stability condition` on the long-run accumulation function by assuming that $\alpha_{1}<s \pi$.

6 The Kaleckian model has been dominant in post-Keynesian economics but has come in for strong criticism, both theoretically and empirically; see, among others, Kurz (1986), Auerbach/Skott (1988) and Skott (20IO and 20I2). A defense of the Kaleckian tradition has been presented by, among others, Lavoie (1995), Dutt (1997), Dallery/van Treeck (2011) and Hein et al. (2012).

$7 \quad$ This specification has been used by Flaschel/Skott (2006) and Ryoo/Skott (2008). 
We abstract from unplanned inventories and rationing in the goods market, neither of which has been seen as important by the three traditions. ${ }^{8} \mathrm{~A}$ shock to demand therefore has to be met by an instantaneous response from the level or price of output. The adjusting variable in the Kaleckian model is the level of output - and hence the utilization rate - which is treated as perfectly flexible. The markup by contrast is fixed. Firms are price setters, and the markup is determined by the sdegree of monopoly`, which the basic Kaleckian model takes as exogenous. With a fixed coefficient production function, the constant markup translates into a fixed profit share:

$$
\pi=\bar{\pi} .
$$

This equation is the Kaleckian version of the general pricing/output condition (4).

Putting together equations (8), (9) and (6) and assuming a dual economy with $\alpha_{3}=0$, we get the standard Kaleckian results: An increase in animal spirits (an increase in $\alpha_{0}$ ) or a decline in the saving rate will raise both utilization and the growth rate. The effects of changes in the markup (the profit share), on the other hand, depends on parameter values, as analyzed by Marglin and Bhaduri (I990).

The mature economy has $\alpha_{3}>0$ and equation (7) is needed to derive the steady-growth solution. Using equations (6) - (9), we get:

$$
\begin{aligned}
& e=\frac{\alpha_{0}+\alpha_{1} \frac{n+\delta}{s \bar{\pi}}+\alpha_{2} \bar{\pi}-n-\delta}{\alpha_{3}}, \\
& u=\frac{n+\delta}{s \bar{\pi}}, \\
& g=n .
\end{aligned}
$$

The growth rate is now exogenous, but an increase in animal spirits or a decline in the saving rate has positive level effects. The utilization rate $u$ is decreasing in $s$, and the employment rate $e$ is increasing in $\alpha_{0}$ and decreasing in $s$. An increase in the markup leads to a fall in utilization while the employment effect is ambiguous. ${ }^{9}$ The explicit solutions in equations (10) - (11) clearly depend on the linear versions of the saving and accumulation functions but the same qualitative results can be obtained with a more general specification; indeed,

8 The absence of rationing in the goods market is consistent with the stylized facts, and unplanned inventories play no role in the long run. Changes in inventories may be important in the short run as a destabilizing force over the cycle, and leaving out this influence may bias the models in the direction of stability.

9 The comparative statics are similar when $n=n(e)$ with $n^{\prime}>0$. The Kaleckian stability condition $\left(\alpha_{1}<s \bar{\pi}\right)$ implies that a unique solution for $e$ can be determined from equation (10) and that the qualitative effects on $e$ of changes in $\alpha_{0}, s$ or $\bar{\pi}$ are unaffected by this extension. Substituting the solution for $e$ into (11) and (12) determines the steady-growth values of $u$ and $g$. 
our dynamic version of the Kaleckian model in the next section allows for non-linearities in the investment function. ${ }^{\text {IO }}$

\subsubsection{Kaleckian dynamics}

While empirical versions of the Kaleckian investment function typically include lags, most theoretical versions specify the accumulation rate as a function of the contemporaneous values of the explanatory variables. Following Dutt (1995), however, the accumulation rate can be treated as a state variable. In this dynamic formulation, the specification (8) is replaced by two equations:

$$
\begin{aligned}
& g^{d}=f(u, \pi, e) ; 0 \leq f_{u}<s \pi, 0 \leq f_{\pi}, f_{e}<0, \\
& \dot{g}=\lambda\left(g^{d}-g\right),
\end{aligned}
$$

where a dot over a variable denotes the rate of change $(\dot{x}=d x / d t)$. Equation (13) defines the desired accumulation rate and equation (14) describes the adjustment process. Equation (13) uses a general functional form (as in equation (3)) but with the Kaleckian restriction on the sensitivity of accumulation to changes in utilization $\left(f_{u}<s \pi\right)$.

The definition of the employment rate and the normalization of labor productivity $(L=Y)$ imply that:

$$
e=\frac{L}{N}=\frac{Y}{N}=\frac{Y}{K} \frac{K}{N}=u k
$$

where $k$ is the ratio of the capital stock to the total labor force and where - using the equilibrium condition for the goods market - the utilization rate is determined by:

$$
u=\frac{g+\delta}{s \bar{\pi}}
$$

The dynamics of $k$ are given by:

$$
\hat{k}=g-n \text {. }
$$

We now get a two-dimensional system of differential equations in $g, k$ :

$$
\begin{aligned}
& \dot{g}=\lambda\left[f\left(\frac{g+\delta}{s \bar{\pi}}, \bar{\pi}, \frac{g+\delta}{s+\bar{\pi}} k\right)-g\right], \\
& \dot{k}=k(g-n) .
\end{aligned}
$$

Io In general, non-linearities can lead to multiple solutions. This is not the case, however, in our Kaleckian model, even in its non-labor constrained form (with $\alpha_{3}=0$ ). To preserve the Kaleckian nature of the model - as we have defined the term - investment must be less sensitive to variations in utilization than saving; for any given markup, the equilibrium condition for the goods market therefore determines a unique solution for $u$. 
This system has a unique stationary point, and the implied steady-growth solutions for $u$ and $e$ are the same as with the static specification of accumulation.

Evaluated at the stationary point, the Jacobian of the system takes the form:

$$
J(g, k)=\left(\begin{array}{cc}
\lambda\left(f_{u} \frac{1}{s \bar{\pi}}+f_{e} \frac{k}{s \bar{\pi}}-1\right) & \lambda f_{e} \frac{n+\delta}{s \bar{\pi}} \\
k & 0
\end{array}\right) .
$$

The Jacobian has a positive determinant and a negative trace, and the stationary point is locally stable. Depending on the precise specification, the convergence may involve damped oscillations, and if this is the case, the oscillations are clockwise in a $g, k$ diagram. More interesting, perhaps, are the predicted patterns for $u$ and $e$. Using the relations between $g, k$ and $u, e$ (equations (15) - (16)), it can be shown that the model produces a clockwise pattern in the $e, u$ plane. $^{\text {II }}$

\subsection{A Robinsonian model}

\subsection{Steady growth}

Our Robinsonian model is derived from Robinson (1956 and 1962) but modified to fit a mature economy. Robinson assumes that the equalization of actual and desired utilization rates is achieved through adjustments in the markup: "competition (in the short-period sense) is sufficiently keen to keep prices at the level at which normal capacity output can be sold " (Robinson 1962: 46). ${ }^{\text {I2 }}$ Taking normal (desired) utilization as exogenous, the argument can be formalized by the following steady-growth version of the pricing equation:

$$
u=u^{d} .
$$

Equation (21) can be obtained as a limiting case of equation (4) by letting the partial derivative with respect to $u$ go to infinity; that is, let $\xi_{u} \rightarrow \infty$ for $u \rightarrow u^{d}$.

Turning to investment, Robinson's verbal argument (I962: 47) implies a steady-growth accumulation function of the form

$$
g=\frac{I}{k}=\psi\left(r^{e}\right)
$$

II Equations (15) - (16) imply that

$$
\begin{aligned}
& \dot{u}=\frac{1}{s \bar{\pi}} \dot{g}=\frac{\lambda}{s \bar{\pi}}[f(u, e)-s \bar{\pi} u+\delta] \\
& \dot{e}=e\left[s \bar{\pi} u-n-\delta+\frac{\lambda}{s \bar{\pi} u}(f(u, e)-s \bar{\pi} u+\delta)\right]
\end{aligned}
$$

The determinant and trace of this system are positive and negative, respectively, and using a phase diagram it is readily seen that oscillations - if they occur - will be clockwise in $(e, u)$-space.

I2 Steindl's (1952) argument is close to Robinson's and includes sluggish adjustments in the markup; see Flaschel/Skott (2006). 
where $r^{e}$ is the expected future rate of profit on new investment and $f^{\prime}>0$. This specification is intended for a dual economy without labor constraints. For a mature economy, the state of the labor market needs to be considered, and we assume that high employment rates (associated with strong workers and a poor business climate) put a damper on accumulation. ${ }^{13}$ Formally:

$$
g=\psi\left(r^{e}, e\right) ; \quad \psi_{r}>0, \psi_{e}<0 .
$$

In steady growth, expectations are being met and $r^{e}=r=\pi u$. Thus:

$$
g=f(u, \pi, e) ; \quad f_{u}>0, f_{\pi}>0, f_{e}<0 .
$$

Using the equilibrium condition for the product market and the maturity condition $(g=n)$, the steady-growth solution for $\pi$ becomes:

$$
\pi=\frac{n+\delta}{s u^{d}},
$$

and the solution for employment is found from:

$$
f\left(u^{d}, \frac{n+\delta}{s u^{d}}, e\right)=n .
$$

The comparative statics can be derived from equations (25) - (26). An increase in the saving rate reduces both the profit share and the employment rate, while an increase in animal spirits (an upward shift in the $f$-function) raises the employment rate. ${ }^{14}$ Note that since the profit share is endogenous, the standard notions of wage or profit led growth do not apply to this model.

\subsubsection{Robinsonian dynamics}

Endogenous changes in the profit share lie behind the steady-growth equality of actual to desired utilization. As a simple formalization we assume that: ${ }^{\text {I5 }}$

$$
\dot{\pi}=\zeta(u) ; \quad \zeta_{u}>0 .
$$

I3 This extension finds support in Robinson's discussion of the factors that may hold down accumulation in the restrained golden ager (Robinson 1962: 54-55).

I4 Endogenous changes in the growth of the labor supply $-n=n(e)-$ can be introduced. With this extension, changes in the employment rate clearly affect the growth rate but other comparative static results are unchanged as long as the growth effect is relatively weak and the total derivative of the $f$-function with respect to $e$ in equation (26) remains negative (i.e. $\left.f_{\pi} n^{\prime} /\left(s u^{d}\right)+f_{e}<0\right)$. An increase in $s$, for instance, reduces $\pi$ and $e$ (as in the specification with a constant value of $n$ ) but the decline in $e$ now leads to a fall in the steady growth rate.

I5 The pricing decisions of a rational firm may take into account both the current level of utilization and the recent rate of change (even if utilization is low, say, there may be no need to reduce prices if utilization rates are already increasing). Thus, one might prefer the more general specification

$$
\dot{\pi}=\zeta(u, \dot{u}) ; \quad \zeta_{u}>0, \zeta_{\dot{u}} \geq 0
$$


This specification includes a standard adjustment equation $-\dot{\pi}=\mu\left(u-u^{d}\right)-$ as a special case.

Investment is also a source of short-run dynamics. Outside steady growth, the distinction between expected and actual profitability in Robinson's argument introduces gradual adjustments in accumulation. In a continuous-time setting, this can be achieved by a dynamic version of the investment function (23),

$$
\begin{aligned}
\dot{g} & =\lambda\left[\psi\left(r^{e}, e\right)-g\right] \\
& =\lambda[f(u, \pi, e)-g]
\end{aligned}
$$

where $\lambda>0$ and $f_{u}>0, f_{\pi}>0, f_{e}<0$, and where the expectational variable $r^{e}$ has been replaced by the current values of the utilization rate and the profit share. ${ }^{16}$

With slow price adjustment, instantaneous movements in the utilization rate $u$ ensure goods market equilibrium, and the rate of utilization is given by:

$$
u=\frac{g+\delta}{s \pi} .
$$

Compared to the Kaleckian system, a dynamic equation for the change in $\pi$ has been added, and we get a three dimensional system of differential equations. The state variables are $g$, $\pi$, $k$ where, as before, the state variable $k$ describes the ratio of the capital stock to the labor force. The dynamics of $k$ are still given by (17), and the system consists of equations (17), (27) and (28), with $u$ and $e$ determined by (29) and (15). The unique stationary state is the one described above.

The local stability properties of the stationary solution are determined by the Jacobian which, evaluated at the stationary solution, takes the form:

$$
J(g, \pi, k)=\left(\begin{array}{ccc}
\lambda\left(f_{u} \frac{1}{s \pi}+f_{e} \frac{k}{s \pi}-1\right) & \lambda\left(-f_{u} \frac{n+\delta}{s \pi^{2}}+f_{\pi}-f_{e} \frac{k(n+\delta)}{s \pi^{2}}\right. & \lambda f_{e} \frac{n+\delta}{s \pi} \\
\zeta^{\prime} \frac{1}{s \pi} & -\zeta^{\prime} \frac{n+\delta}{s \pi^{2}} & 0 \\
k & 0 & 0
\end{array}\right) .
$$

The necessary and sufficient Routh-Hurwitz conditions for local stability of the linearized system are that:

1) $\operatorname{Tr}(J)=\lambda\left(f_{u} \frac{1}{s \pi}+f_{e} \frac{k}{s \pi}-1\right)-\zeta^{\prime} \frac{n+\delta}{s \pi^{2}}<0$,

2) $\operatorname{Det}\left(J_{1}\right)+\operatorname{Det}\left(J_{2}\right)+\operatorname{Det}\left(J_{3}\right)=\lambda \zeta^{\prime} \frac{1}{s \pi}\left(\frac{n+\delta}{\pi}-f_{\pi}\right)-k \lambda f_{e} \frac{n+\delta}{s \pi}>0$,

The theoretical model does not use this formulation since the utilization rate is a jump variable in the Robinsonian model. The discrete-time regressions in section 3, however, allow for lagged values of the utilization rates in the Robinsonian pricing equation.

I6 See Skott (2005b) for a more detailed discussion of this dynamic version of Robinson's accumulation function. 
3) $\operatorname{Det}(J)=k \zeta^{\prime} \frac{n+\delta}{s \pi^{2}} \lambda f_{e} \frac{n+\delta}{s \pi}<0$,

4) $-\operatorname{Tr}(J)\left[\operatorname{Det}\left(J_{1}\right)+\operatorname{Det}\left(J_{2}\right)+\operatorname{Det}\left(J_{3}\right)\right]+\operatorname{Det}(J)>0$.

Condition 3 is always satisfied, but one or more of the other three conditions may be violated; the outcome depends on functional forms and parameter values. ${ }^{17}$ Simulations indicate that stable limit cycles can be generated for plausible functional forms and parameter values. To facilitate comparison with the stylized facts in Section 3, the example in Figure I shows the results for $(e, u),(e, \pi)$ and $(u, \pi)$. The simulation assumes that the adjustment function for the profit share is linear. The accumulation function, however, is taken to be s-shaped as a function of profitability (the concavity for high values of profitability is consistent with Robinson's banana-diagram, while the convexity at low levels reflects a lower limit on gross investment), and variations in employment are assumed to have little effect on accumulation at low levels of $e^{\text {. }}{ }^{8}$

\section{Figure I: Robinson simulation}

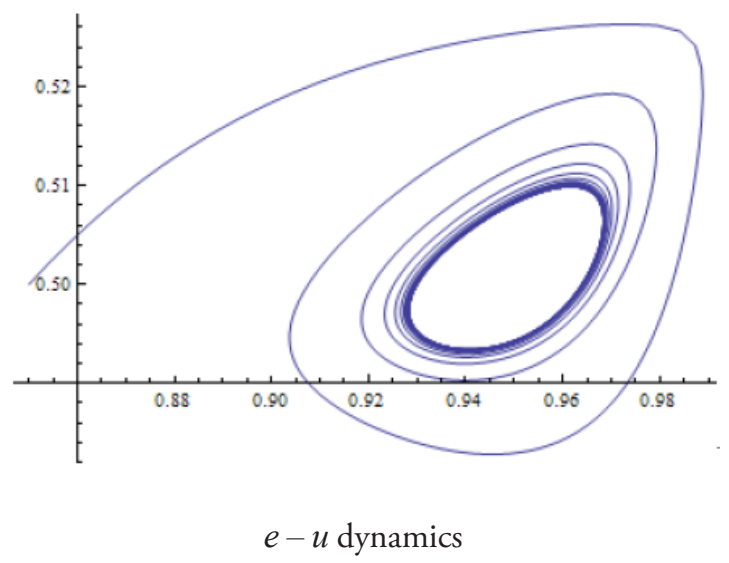

I7 Bifurcation theory is sometimes used to show the existence of limit cycles in cases like this, but Hopf bifurcations describe local behavior and say little about the existence of meaningful economic cycles.

I8 The functional forms, parameters and initial values are:

$$
\begin{aligned}
& f(u, \pi, e)=\frac{0.4}{1+\exp \left(-10\left(\pi-0.1(1-e)^{-0.5}\right)\right)}-0.1 \\
& \xi(u, \dot{u})=10(u-0.5+0.7 \dot{u} / u) \\
& \lambda=2, s=0.7, \delta=0.1, n=0.03 \\
& g(0)=0.04, \pi(0)=0.4, k(0)=1.7
\end{aligned}
$$



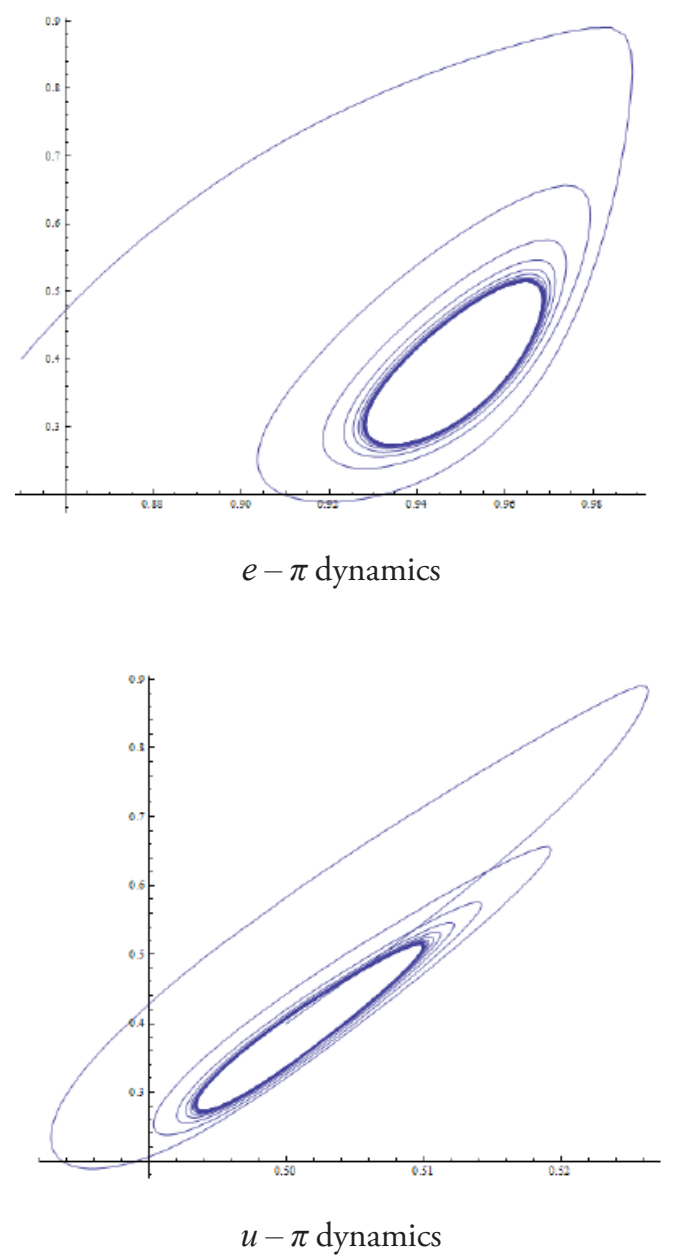

\subsection{A Kaldorian model}

\subsection{Steady growth}

The Kaldorian model assumes that changes in output take time while the adjustment of prices is 'fast $<$. Shocks to aggregate demand are accommodated by movements in prices and profit shares, rather than in output and utilization, but these impact effects are followed by adjustments of output. Mathematically, output becomes a state variable and firms choose the rate of growth of output, rather than the level of output, at each moment. 
Formalizing these arguments, Skott (1989a and 1989b) specified the pricing-output decision as a relation between output growth and the signals that firms receive from the goods market (the profit share) and the labor market (the employment rate): ${ }^{19}$

$$
\hat{Y}=h(\pi, e) ; h_{\pi}>0, h_{e}<0 .
$$

This growth function (or >output expansion function` in the Skott (1989a) terminology) is the Kaldorian version of equation (4). A standard Kaleckian markup equation emerges as a special case of equation (31) when $h_{\pi} \rightarrow \infty$ at $\pi=\bar{\pi}$ and $h_{e} \equiv 0 .{ }^{20}$

Adopting a Harrodian perspective on investment, the model assumes that deviations of actual from desired utilization lead to changes in the accumulation rate. The desired utilization rate may depend on the growth rate, but the sensitivity of desired utilization to changes in $g$ is taken to be small or equivalently, the sensitivity of the long-run accumulation rate to changes in $u$ is high. Algebraically, the steady-growth accumulation function takes the form:

$$
g=\phi(u) ; \quad \phi^{\prime} \geq 0
$$

The steady-growth solution for $u$ can be found by substituting $g=n$ into (32); the solution for $\pi$ can now be calculated from the equilibrium condition for the product market $(\pi=(n+\delta) / s u)$ and the solution for employment from the growth function (31) with $n=\hat{Y}=h\left(\frac{n+\delta}{s u}, e\right) .^{21}$

The comparative statics are similar to those for the Kaleckian and Robinsonian models. A rise in the saving rate generates a fall in both the profit share and the employment rate; an increase in animal spirits (an upward shift in the growth function $h$ and/or in the $\phi$-function) raises the employment rate, and an upward shift in $\phi$ also leads to an increase in the profit share; an increase in worker militancy or labor market frictions (a downward shift in $h$ ) reduces employment but leaves the profit share unchanged. ${ }^{22}$ Distribution is

The behavioral foundations of the function are discussed in detail in Skott (1989a, chapter 4).

20 As with a standard markup equation, the sectoral composition of the economy and the degree of competition in the product markets may affect the position and shape of the growth function.

2I A steady-growth solution exists and is meaningful (has $0<\pi<1$ and $0<e<1$ ) if $0<\frac{n+\delta}{s \phi(n)}<1$ and $h\left(\frac{n+\delta}{s \phi(n)}, 0\right)>n>h\left(\frac{n+\delta}{s \phi(n)}, 1\right)$. The inequalities $0<\frac{n+\delta}{s \phi(n)}<1$ are met for all plausible values of the parameters, and if $e=1$ it is logically impossible for the rate of growth of employment to exceed the rate of growth of the labor force: As $e$ increases it becomes progressively more difficult to expand employment, and the growth function must satisfy the inequality $n>h\left(\frac{n+\delta}{s \phi(n)}, 1\right)$. A capitalist economy may not, however, be capable of growth at the natural rate, and the condition $h\left(\frac{n+\delta}{s \phi(n)}, 0\right)>n$ need not be satisfied. The likelihood of this outcome increases for low values of the natural rate and high saving rates. Japan's stagnation since about 1990 may be related to structural demand problems of this kind (Nakatani/Skott 2007). We ignore this complication and assume that the steady growth equations have a solution with $e>0$.

22 Endogenous changes in the growth of the labor force can be introduced. Changes in $e$ now have growth effects but as in the Kaleckian and Robinsonian cases, other comparative statics are qualitatively unaffected as long as the growth effect is relatively weak. 
endogenous, as in the Robinsonian model, and it makes no sense to talk about wage- or profit-led regimes. Some exogenous shifts generate a positive association between profits and employment while other shifts can produce a negative association (e.g. a combination of increasing worker militancy and falling saving rates). ${ }^{23}$

\subsubsection{Kaldorian dynamics}

Firms want to move towards their desired utilization rate but - as in the Kaleckian and Robinsonian formulations - we take the accumulation rate as predetermined at any moment and assume that the rate of change of accumulation depends on the difference between a target rate $\left(g^{d}\right)$ and actual accumulation. Algebraically:

$$
\dot{g}=\frac{d}{d t} \hat{K}=\lambda\left[g^{d}-g\right] .
$$

The change in the utilization rate depends on the difference between output growth and accumulation, and the specification of the target rate $g^{d}$ therefore includes both the utilization rate and the growth rate of output:

$$
g^{d}=\chi(u, \hat{Y}) ; \quad 0<\chi_{u}, \quad 0 \leq \chi_{\hat{Y}}<1 .
$$

Some fraction of current output growth will be in response to demand shocks that are seen as transitory, and we assume that the partial derivative with respect to $\hat{Y}$ is less than one. The formulation in equations (33) - (34) is consistent with the steady-growth equation (32). At a steady growth path we have $g=\hat{Y}=g^{d}$, and substituting these conditions into equation (34) yields $g=\chi(u, g)$.Thus, we get a steady-growth relation $g=\phi(u)$ where $\phi^{\prime}=\chi_{u} /\left(1-\chi_{\hat{Y}}\right)$.

The model produces a three-dimensional dynamic system in $(g, u, e)$ :

$$
\begin{aligned}
& \dot{g}=\lambda[\chi(u, h(\pi, e))-g], \\
& \dot{u}=u[h(\pi, e)-g], \\
& \dot{e}=e[h(\pi, e)-n],
\end{aligned}
$$

where $\pi=(g+\delta) / s u$. Evaluated at a stationary point the Jacobian of the system takes the form:

$$
J(g, u, e)=\left(\begin{array}{ccc}
\lambda\left[\chi_{\hat{Y}} h_{\pi} \frac{1}{s u}-1\right] & \lambda\left(\chi_{u}-\chi_{\hat{Y}} h_{\pi} \frac{n+\delta}{s u^{2}}\right] & \lambda \chi_{\hat{Y}} h_{e} \\
u\left[h_{\pi} \frac{1}{s u}-1\right] & -u h_{\pi} \frac{n+\delta}{s u^{2}} & u h_{e} \\
e h_{\pi} \frac{1}{s u} & -e h_{\pi} \frac{n+\delta}{s u^{2}} & e h_{e}
\end{array}\right) .
$$

As in the Robinsonian case, the conditions for local stability will not be met in general, and the model can produce stable limit cycles. An example is provided in Figure 2 which shows 
292

Intervention. European Journal of Economics and Economic Policies

Figure 2: Kaldorian simulation

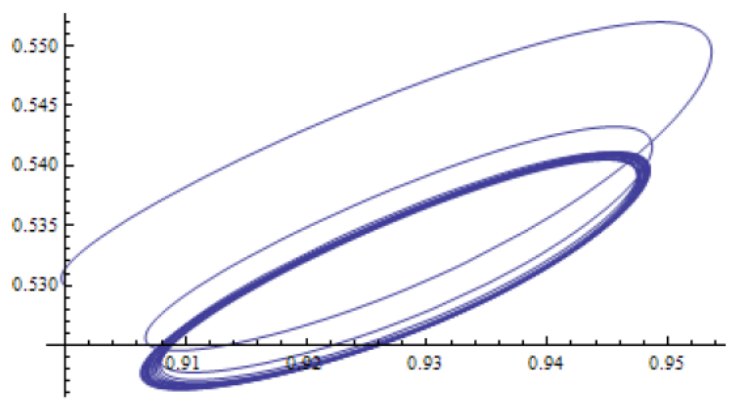

$e-u$ dynamics

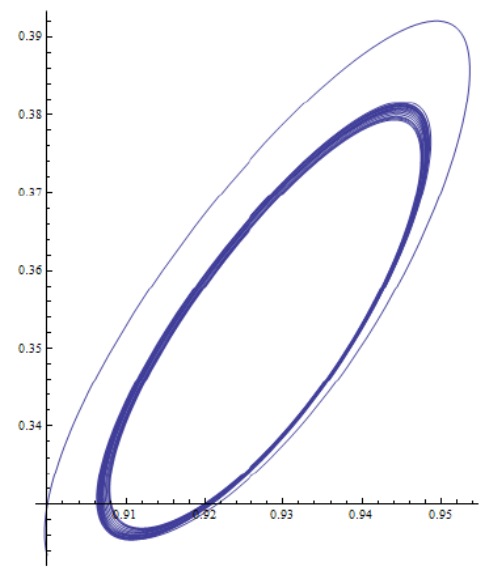

$e-\pi$ dynamics

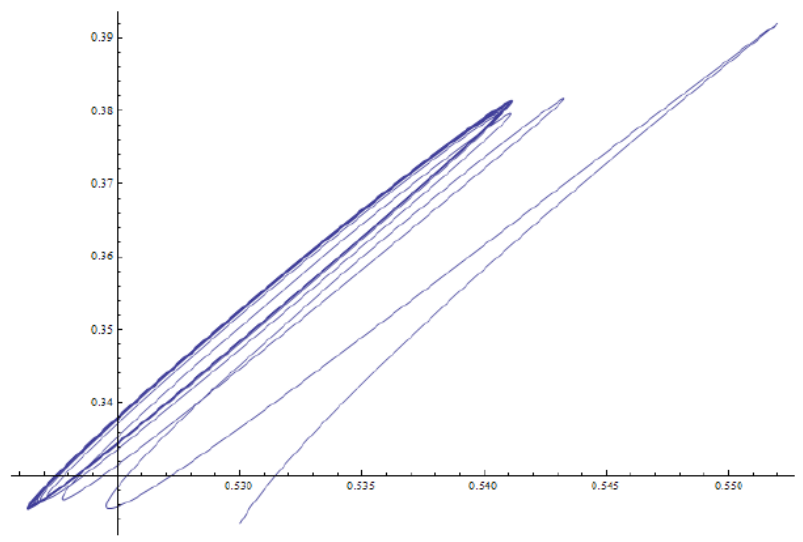

$u-\pi$ dynamics

Downloaded from PubFactory at $04 / 26 / 2023$ 02:16: 07 PM

via free access 
the simulated patterns for $(e, u),(e, \pi)$ and $(u, \pi)$ respectively. The simulation assumes a linear accumulation function, but the growth function is s-shaped. Adjustment costs for output are likely to be convex as a function of $\hat{Y}$ - there may even be upper and lower limits on the rate of growth, $g^{\min } \leq \hat{Y} \leq g^{\max }$ - and the growth rate will be more sensitive to variations in the profit share for intermediate values of the profit share than for very high or very low values. We also assume that marginal variations in employment have small effects unless the economy is close to full employment. (These assumptions parallel the assumptions in the Robinsonian simulation: The equation that keeps long-run utilization at the desired rate is kept linear while the other equation is s-shaped and has an employment effect that is weak at low levels of $e$. $)^{24}$

\section{Evaluation}

\section{I Stylized patterns}

An empirical evaluation of abstract models raises difficult questions. One obvious problem concerns appropriate definitions of the empirical counterparts to the theoretical variables. Data issues of this kind are discussed by Zipperer and Skott (20II) who also provide a description of the stylized facts for accumulation, utilization, profitability and employment. ${ }^{25}$ In this paper we confine ourselves to a brief outline of the main findings.

The US patterns are quite clear and consistent, and many of the patterns exist, but are generally not as clean and consistent, for other OECD countries too. ${ }^{26}$ For the US

24 The figure is based on the following specifications

$$
\begin{aligned}
& \chi(u, \hat{Y})=0.3(u-0.5)+0.7 \hat{Y} \\
& \hat{Y}=h(\pi, e)=\frac{0.4}{1+\exp \left(-15\left(\pi-0.2-0.04(1-e)^{-0.5}\right)\right)}-0.17 \\
& \lambda=1, \quad n=0.03, \quad s=0.7, \quad \delta=0.1
\end{aligned}
$$

and initial values $u(0)=0.53, e(0)=0.9, g(0)=0.02$. The logistic specification of the growth function is symmetric around the steady-growth rate, and the parameters imply that $\hat{Y}$ has upper and lower bounds of 23 and -I7 percent, respectively. The maximum sensitivity to changes in the profit share (the maximum value of $\partial \hat{Y} / \partial \pi$ ) is I.5. The sensitivity with respect to employment goes to infinity as employment approaches one and it may be more informative to look at the transformed variable $E=(1-e)^{-0.5}$; the specification implies a maximum sensitivity with respect to $E$ of -0.06 . The accumulation function implies a steady-growth sensitivity of $d g / d u=1$ (in steady growth $g=\hat{Y}$ and hence $g=0.3(u-0.5)+0.7 g)$.

25 See also Barbosa-Filho/Taylor (2006) and Mohun/Veneziani (2008). These studies use the Goodwin model as their theoretical framework; the former focusing exclusively on oscillations in profits and utilization, and the latter on profits and employment.

26 Less consistent patterns are to be expected in economies that are small and/or have large public sectors. 
a) the employment rate, the profit share and the utilization rate fluctuate around a mean of about 0.94, 0.28 and 0.8 I respectively;

b) the long-term trends of the variables exhibit modest variation;

c) short-term fluctuations are significant for all the variables but the amplitudes differ: typically less than 6 percentage points over a cycle for employment and the profit share and up to $15-20$ percentage points for utilization. In proportional terms, the amplitude is similar for utilization and the profit share but much smaller for employment;

d) there is strong evidence of clockwise short-term cycles in three bivariate spaces: $(e, \pi)$, $(e, u)$, and $(u, \pi)$;

e) the short-term cycles are synchronized with the standard NBER dating of business cycles;

f) the cyclical patterns appear to be quite robust to changes in the precise definition and measurement of the variables.

Looking first at the Kaleckian model, the clockwise pattern of $(e, u)$ is consistent with the predicted dynamics. The Kaleckian model says nothing about the movements in $\pi$ however, and another stylized fact poses problems for the model. Observed utilization rates exhibit fluctuations, but the fluctuations take place around a trend that seems roughly flat. From the perspective of the Kaleckian model, this feature of the data is surprising since the model predicts (potentially large and persistent) changes in utilization following shifts in demand parameters (including saving rates). Empirically, such demand shifts do seem to have occurred, and the absence of significant long term changes in utilization would have to be explained as the result of mutually offsetting shifts in different parameters.

Both the Robinsonian and Kaldorian formulations in Section 2 have utilization at the desired rate in steady growth - which is in line with the relative long-term stability of utilization - and both versions endogenize the profit share. The steady-growth equality between desired and actual utilization is based on pricing/output behavior in Robinson and on accumulation in Kaldor; to get a steady-growth relation between growth and profitability, conversely, the Robinsonian model uses capital accumulation instead of output growth, as in the Kaldorian version. But from a steady-growth perspective these changes in the assignment of pricing and accumulation make no difference.

The differences in the relative adjustment speeds for output and prices affect the shortrun dynamics of the models. Figures $\mathrm{I}-2$, however, show that with suitable choices of parameter values the cyclical patterns for employment, utilization and the profit share can be qualitatively similar and broadly in line with the empirical evidence.

A possible problem with the Robinsonian model is the failure of our simulations to reproduce clockwise cycles in the $(u, \pi)$ space. This failure has an intuitive explanation: A positive relation between the change in $\pi$ and the level of $u$ produces a tendency toward counter clockwise cycles, and adding the rate of change of $u$ as an influence on $\dot{\pi}$ does not remove this tendency. The significance of this shortcoming of the Robinsonian model 
relative to the Kaldorian formulation should not be exaggerated. It may be possible to achieve clockwise cycles with relatively minor modifications of the Robinsonian model; it should be noted, moreover, that the orientation of the $(u, \pi)$ cycle is reversed in the Kaldorian model if the effect of output growth is excluded from the accumulation function. The qualitative properties of the $(e, u)$ and $(e, \pi)$ cycles, by contrast, are robust. ${ }^{27}$

Both simulations deviate from the stylized patterns in some respects. The amplitude of fluctuations in the employment rate (relative to the amplitude of the fluctuations in utilization) is lower in the data than in the simulated cycles. Okun's law provides a simple explanation for this discrepancy. The models exclude variations in the utilization of labor and assume constant labor productivity (or a constant rate of growth of labor productivity). Actual labor productivity, by contrast, is strongly procyclical, and to incorporate this empirical regularity, the dynamic equation for the employment rate could be respecified as

$$
\begin{aligned}
\hat{e} & =\hat{L}-n \\
& =[\lambda(\hat{Y}-n)+n]-n ; \quad \lambda<1 .
\end{aligned}
$$

Simulations with this modified equation reduce the amplitude of the employment cycle.

The amplitude of the profit cycle is also too high in the simulations. This discrepancy is not surprising either. The models treat investment as the only source of autonomous demand in the short run, but both the foreign and public sectors are important, even in a relatively closed, small-government economy like the US. A significant part of foreign and public demand is independent of the level of output in the short run; demand originating from these sectors affects the equilibrium condition for the product market and the determination of the profit share. If, as a simple example, all foreign and public demand is proportional to the capital stock, the determination of the profit share in the Kaldorian model $-\pi=(g+\delta) / s u-$ is replaced by:

$$
\pi=\frac{g+\delta+a}{s u} ; \quad a>0,
$$

where $a$ is the ratio of foreign and public demand to capital. Simulations show that this modification reduces the amplitude of the profit cycle relative to the amplitude of utilization. ${ }^{28}$

Overall, the successful reproduction by the models of some of the striking empirical patterns is promising. But as pointed out by critics of the calibration approach, the ability of a calibrated model to simulate selected empirical patterns provides a weak test of the

27 As is well known, simulation results can be sensitive to choices of functional form and parameter values. Our simulations introduced only non-linearities based on strong economic arguments (the effects of marginal changes in employment, for instance, will depend on the initial level of employment). Given the chosen functional forms, we examined a range of parameter values. We did not, however, carry out a systematic analysis of how changes in functional forms and variations in parameter values affect the results.

28 Other simple extensions with similar effects allow for private sector saving out of wage income and public sector expenditure that is related inversely to the employment rate. 
model. Furthermore, the similarity of the reduced-form dynamics does not mean that the underlying behavioral equations of Kaldorian and Robinsonian specifications perform equally well empirically.

\subsection{Regressions}

\subsection{Output and pricing}

Our benchmark Kaleckian model takes the markup as constant. This assumption does not fit the evidence, but it would be unreasonable to treat the constant markup as a theoretical prediction. It seems more accurate to interpret the basic Kaleckian model as being silent on this issue. The Robinsonian and Kaldorian models, by contrast, endogenize the pricing/ output decision. The Kaldorian model assumes that output growth responds to profitability and employment, while the Robinsonian argument relates changes in the profit share to the rate of utilization. These different views on the determinants of pricing and output can be examined econometrically.

The Kaldorian regression has output growth as the dependent variable; the deviation of the profit share from its long-term trend and the deviation of a non-linear indicator of labor market conditions, $E=(1-e)^{-0.5}$ from its long-term trend are the regressors. ${ }^{29} \mathrm{We}$ use the deviation from trends to control for unobserved movements in structural variables (including changes in the degree of product market competition and shifts in the power of unions) that influence the long-run pricing/output decision. ${ }^{30}$ As a robustness check, regressions were also run using actual values of the explanatory variables rather than the deviations from trend; this change in the specification has only minor impacts on the significance of variables, but tends to lower the impact of most variables (we describe a specific case in the accumulation regressions). The reasoning behind the non-linearity in the labor market indicator is straightforward: A one percentage point increase in employment represents a significant tightening of the labor market at an initial unemployment rate of, say, 4 percent, but that same percentage point change is unlikely to make much difference if the initial position is one of 20 percent unemployment. We ran regressions using other functional forms for the labor market indicator, and the empirical results were insensitive to these changes in the precise specification.

The results of the Kaldorian regressions are in Table I. The profit share and output growth are for the non-financial business sector (NFCB) and exclude production taxes, and the employment rate $e$ is measured as one minus the seasonally adjusted unemployment rate

29 This specification is a linearized version of the one used in the simulations (which assumed that output growth was a function of $\pi-a-b(1-e)^{-0.5}$.

30 Trends are calculated using HP filters with 129,600 as the smoothing parameter. This parameter has been used in the literature; the parameter choice is largely arbitrary, however, and the results are insensitive to the changes in the precise value. The long-term trend is restricted to 1953-200I to avoid well-known problems near the endpoints; thus the long-term trend begins and ends close to the 1953q2 and 200IqI NBER business peaks. 
from the Bureau of Labor Statistics (BLS). Column I corresponds to the basic specification in equation (31). ${ }^{31}$ Both the profit share and the labor market indicator have the expected signs and are significant at the I\% level. The growth rate is quarterly, and a one percentage point increase in $\pi$ and $E$ change the annual growth rate by about I. 4 and 0.07 percentage points, respectively. The regression shows signs of autocorrelation in the error terms, according to the reported Breusch-Godfrey tests for lags one through four, and all reported standard errors are adjusted using Newey-West technique. We tried to eliminate the autocorrelation by adding lagged values of the independent variable. This introduced multicollinearity and failed to solve the problem. As an alternative, we included a lagged dependent variable (which captures infinitely many lags). Lagged dependent variables can bias the estimates, but absent any serial correlation problems, the OLS estimates are still consistent, and the bias concerns are eased by the relatively large number of observations (close to 200). The results are in column 2 . The autocorrelation problem is alleviated and the fit is improved. The coefficients on $\pi$ and $E$ are reduced slightly, but keep their signs and statistical significance.

The long-term effect in column 2 is smaller than the effect in column I: a one percentage point increase in the profit share raises the quarterly growth rate of output by about 0.25 percentage points (corresponding to an increase in the annual growth rate of about I percentage points); a unit increase in the labor market indicator reduces the annual growth rate by about 6 percentage points. Using the mean of $E$ in the 1953-200I sample, this effects translates into a 6 percentage point output growth loss when the employment rate $e$ increases from 94.5 percent to 96.4 percent.

To check robustness, we tried several specifications that included the utilization rate as an explanatory variable. ${ }^{32}$ Here, utilization is calculated as NFCB output divided by its smoothed series. The coefficient on this measure of utilization is significantly negative in column 3. When lagged values of $\hat{Y}$ are added to the estimation in column 4 , the long-run effect of profit shares on output growth is largely unaffected (a one percentage point increase in $\pi$ raises annual growth by about I.4 percentage points). The impact of utilization strengthens and employment is no longer statistically significant, but the deviations of actual output from trend may provide a poor proxy for utilization and there may be significant collinearity between this measure and employment. In other regressions, we tried the Federal Reserve data on utilization rates in manufacturing. This alternative measure produced negative but statistically insignificant effects and had only minor effects on the estimated profit and employment parameters. ${ }^{33}$

3I The growth rate of output is defined as the forward difference, $\hat{Y}_{\mathrm{t}}=\log Y_{t+1}-\log Y_{t}$.

32 From a theoretical perspective, the growth rate of output (rather than the deviation of the growth rate from its trend) is the appropriate dependent variable. But we also tried the same set of regressions with deviations of output growth as dependent and lagged dependent variables; the results were very similar.

33 A negative effect of utilization on output growth could arise in the Kaldorian model because high utilization rates lead to capacity constraints in a significant proportion of firms. 
Overall, the parameters in the simulations of the Kaldorian system in Figure 2 are in line with the empirical estimates. The growth equation is nonlinear but evaluated at the steady growth path (where the sensitivity of growth to changes in $\pi$ and $E$ at its maximum), the derivatives of the simulated equation are given by $\partial \hat{Y} / \partial \pi=\mathrm{I} .5$ and $\partial \hat{Y} / d E=-0.06$.

Table I: Kaldorian output growth

\begin{tabular}{|c|c|c|c|c|}
\hline VARIABLES & $\begin{array}{l}\text { (1) } \\
\text { yhat }\end{array}$ & $\begin{array}{l}(2) \\
\text { yhat }\end{array}$ & $\begin{array}{l}\text { (3) } \\
\text { yhat }\end{array}$ & $\begin{array}{l}\text { (4) } \\
\text { yhat }\end{array}$ \\
\hline E dev & $\begin{array}{c}-0.0169 * * * \\
(0)\end{array}$ & $\begin{array}{c}-0.0136 * * * \\
(2.35 \mathrm{e}-07)\end{array}$ & $\begin{array}{c}-0.00929 * * * \\
(0.00582)\end{array}$ & $\begin{array}{c}-0.00216 \\
(0.535)\end{array}$ \\
\hline pi_dev & $\begin{array}{l}0.355^{* * * *} \\
(5.94 \mathrm{e}-08)\end{array}$ & $\begin{array}{c}0.231^{* * *} \\
(0.00741)\end{array}$ & $\begin{array}{l}0.425 * * * \\
(2.34 \mathrm{e}-10)\end{array}$ & $\begin{array}{c}0.190^{* *} \\
(0.0206)\end{array}$ \\
\hline L.yhat & & $\begin{array}{c}0.220 * * * \\
(0.00430)\end{array}$ & & $\begin{array}{c}0.360^{* * *} \\
(4.89 \mathrm{e}-06)\end{array}$ \\
\hline L3.yhat & & $\begin{array}{l}0.0811 \\
(0.224)\end{array}$ & & $\begin{array}{c}0.175^{* * *} \\
(0.00835)\end{array}$ \\
\hline L4.yhat & & $\begin{array}{c}-0.186^{* * *} \\
(0.00428)\end{array}$ & & $\begin{array}{c}-0.0997 \\
(0.121)\end{array}$ \\
\hline yy_u & & & $\begin{array}{l}-0.174 * * * \\
(0.000863)\end{array}$ & $\begin{array}{c}-0.267^{* * * *} \\
(2.73 \mathrm{e}-06)\end{array}$ \\
\hline Constant & $\begin{array}{c}0.00997^{* * * *} \\
(0)\end{array}$ & $\begin{array}{c}0.00880 * * * \\
(3.14 \mathrm{e}-08)\end{array}$ & $\begin{array}{c}0.0100 * * * \\
(0)\end{array}$ & $\begin{array}{c}0.00563 * * * \\
(0.000664)\end{array}$ \\
\hline Observations & 196 & 196 & 196 & 196 \\
\hline R-Squared & 0.223 & 0.278 & 0.261 & 0.348 \\
\hline Prob $>F$ & 0 & 0 & 0 & 0 \\
\hline BG-L1 P > $\chi^{2}$ & 0.0200 & 0.376 & 0.000788 & 0.230 \\
\hline BG-L2 P > $\chi^{2}$ & 0.0613 & 0.226 & 0.00286 & 0.462 \\
\hline BG-L3 P > $\chi^{2}$ & 0.0691 & 0.366 & 0.000656 & 0.670 \\
\hline BG-L4 P $>\chi^{2}$ & 0.0279 & 0.471 & 0.00108 & 0.810 \\
\hline
\end{tabular}

p-values in parentheses

${ }^{* * *} \mathrm{p}<0.0 \mathrm{I},{ }^{* *} \mathrm{p}<0.05,{ }^{*} \mathrm{p}<0 . \mathrm{I}$

The results for the Robinsonian regression are given in Table 2. The dependent variable is the change of the NFCB profit share, and utilization is measured as NFCB output divided by its trend. None of the specifications in Table 2 exhibit serial correlation problems. Column one includes only the utilization rate, corresponding to the theoretical specification in equation (27). The coefficient on the rate of utilization is statistically significant but negative, in contrast to the Robinsonian theory. This incorrect sign carries over to all specifications in Table 2. Column 2 shows that changes in utilization enter positively (see footnote II) but only with a p-value of 0.I5. When a lagged dependent variable is included, as in column 3, 
the significance of the changes in utilization improves, but the effect of utilization remains negative. Columns 4 through 6 are a sample of more general specifications that include deviations of the profit share and labor market indicator from their long-term trends. The negative sign on $E$, while not always statistically significant, is what one would expect, given the empirically observed clockwise cycles in $\pi$.

The regressions in Table 2 fail to support the Robinsonian hypothesis of a positive relation between utilization and changes in the profit share. Needless to say, this result does not imply a rejection of the Robinsonian/Kaleckian view of output as the fast variable and the markup as a slow variable. It may be possible to tell a story in which pricing decisions generate the observed movements in the profit share. One approach could be to look at separate specifications for nominal wage rates, nominal prices and labor productivity (Flaschel/Krolzig 2006), although the stubbornly negative coefficient on utilization in Table 2 may be hard to rationalize.

Table 2: Robinsonian price adjustment

\begin{tabular}{|c|c|c|c|c|c|c|}
\hline VARIABLES & $\begin{array}{c}\text { (1) } \\
\text { FD.pi_dev }\end{array}$ & $\begin{array}{c}\text { (2) } \\
\text { FD.pi_dev }\end{array}$ & $\begin{array}{c}\text { (3) } \\
\text { FD.pi_dev }\end{array}$ & $\begin{array}{c}\text { (4) } \\
\text { FD.pi_dev }\end{array}$ & $\begin{array}{c}\text { (5) } \\
\text { FD.pi_dev }\end{array}$ & $\begin{array}{c}(6) \\
\text { FD.pi_dev }\end{array}$ \\
\hline yy_u & $\begin{array}{c}-0.146^{* * *} \\
(0)\end{array}$ & $\begin{array}{c}-0.153^{* * *} \\
(0)\end{array}$ & $\begin{array}{c}-0.166^{* * *} \\
(0)\end{array}$ & $\begin{array}{c}-0.141^{* * * *} \\
(9.94 \mathrm{e}-08)\end{array}$ & $\begin{array}{c}-0.119 * * * \\
(8.50 \mathrm{e}-08)\end{array}$ & $\begin{array}{c}-0.129 * * * * \\
(1.63 e-07)\end{array}$ \\
\hline D.yy_u & & $\begin{array}{c}0.0457 \\
(0.129)\end{array}$ & $\begin{array}{l}0.101^{*} \\
(0.0504)\end{array}$ & $\begin{array}{c}0.0902 \\
(0.101)\end{array}$ & & $\begin{array}{c}0.0306 \\
(0.342)\end{array}$ \\
\hline pi_dev & & & & $\begin{array}{c}-0.00532 \\
(0.875)\end{array}$ & & \\
\hline E_dev & & & & $\begin{array}{c}-0.00221 \\
(0.185)\end{array}$ & $\begin{array}{c}-0.00262 * \\
(0.0804)\end{array}$ & $\begin{array}{c}-0.00206 \\
(0.199)\end{array}$ \\
\hline D.pi_dev & & & $\begin{array}{l}-0.137 \\
(0.188)\end{array}$ & $\begin{array}{l}-0.145 \\
(0.161)\end{array}$ & & \\
\hline Constant & $\begin{array}{c}-9.32 \mathrm{e}-05 \\
(0.841)\end{array}$ & $\begin{array}{c}-7.72 \mathrm{e}-05 \\
(0.867)\end{array}$ & $\begin{array}{c}-6.98 \mathrm{e}-05 \\
(0.880)\end{array}$ & $\begin{array}{c}-7.44 \mathrm{e}-05 \\
(0.872)\end{array}$ & $\begin{array}{c}-7.88 \mathrm{e}-05 \\
(0.864)\end{array}$ & $\begin{array}{c}-7.12 \mathrm{e}-05 \\
(0.877)\end{array}$ \\
\hline Observations & 195 & 195 & 194 & 194 & 195 & 195 \\
\hline R-Squared & 0.298 & 0.302 & 0.302 & 0.302 & 0.305 & 0.304 \\
\hline Prob $>F$ & 0 & 0 & 0 & 0 & 0 & 0 \\
\hline BG-L1 P> $\chi^{2}$ & 0.971 & 0.222 & 0.710 & 0.928 & 0.618 & 0.178 \\
\hline BG-L2 P> $>\chi^{2}$ & 0.970 & 0.414 & 0.840 & 0.814 & 0.698 & 0.292 \\
\hline BG-L3 P> $>\chi^{2}$ & 0.723 & 0.271 & 0.483 & 0.531 & 0.623 & 0.246 \\
\hline BG-L4 P> $>\chi^{2}$ & 0.652 & 0.385 & 0.503 & 0.527 & 0.578 & 0.338 \\
\hline
\end{tabular}




\subsubsection{Investment functions}

All three benchmark models explain accumulation as a function of $u, \pi$ and $e$ and they all allow gradual adjustment (equations (18), (28) and (35)). Despite this similarity, there are crucial differences. Both the Kaldorian and Robinsonian approach regard the desired utilization rate as structurally determined. This structural determination is rejected by Kaleckian models which treat the utilization rate as an accommodating variable and assume that long-run accumulation is less sensitive than the saving-capital ratio to variations in the utilization rate.

Tables 3-4 present the investment regressions. There are two candidate data series for the capital stock: Bureau of Economic Analysis (BEA) net fixed assets and the Federal Reserve (Fed) industrial capacity index. The Fed series is available for the manufacturing sector (or, with a shorter time range, for total industry). While the Fed series is monthly, the BEA data are annual. Low frequency is a serious disadvantage for the analysis of cyclical patterns, and there may also be other reasons to prefer the Fed data. Heterodox models usually assume a fixed coefficient production function and a constant rate of depreciation. If these assumptions are satisfied, indicators of production capacity (the Fed data) and capital stock (BEA) will coincide, if correctly measured. If the assumptions are relaxed, however, the two indicators can deviate, and the economic argument behind the standard investment functions concerns the desired increase in capacity. For our purposes, at least, the Fed data therefore may be preferable on theoretical grounds (as well as because of their high frequency). ${ }^{34}$

Table 3 uses the Fed series. Column I corresponds to the theoretical specifications in equations (18), (28) and (35). The dependent variable is the rate of change of manufacturing capacity. Deviations of manufacturing utilization, overall employment, and NFCB profit shares from their trends are highly significant and have the expected signs. The very strong persistence of capacity shows up in the high coefficient for the lagged dependent variable. The specification in column I exhibits serial correlation that could bias the coefficient estimates, given the lagged endogenous variable. Additional lags of capacity changes in column 2 eliminate the autocorrelation, lower the short-run effects of the independent variables, and have modest impacts on the long-run effects. A one percentage point increase in $u$ and $\pi$ generates a change in the steady growth value of the annual accumulation rate of about 0.9 to I.3 and I.O to I.3; a unit increase in $E$ reduces accumulation by 8 to Io percentage points.

Using actual values of $u, e$ and $\pi$ rather than deviations from long-term trend somewhat lowers the long-term impact of utilization on $\hat{K}$. For example, with actual values the analogous specification in columns $\mathrm{I}-2$ of Table 3 implies that a one percentage point increase of $u$ raises the annual accumulation rate by 0.46 to 0.68 percentage points.

Since manufacturing sector profits are unavailable at a quarterly frequency, we used NFCB profit shares in columns I and 2. We address this sectoral inconsistency in two ways in columns $3-6$. In columns $3-4$ we simply drop the profit share from the specification,

34 The capacity index measures the "greatest level of output a plant can maintain within the framework of a realistic work schedule« (http://www.federalreserve.gov/releases/gI7/cap_notes.htm). To calculate quarterly capacity changes $\hat{K}$ from the monthly capacity data, we calculate the percent difference between index values three months apart. 
and in columns $5-6$ we use the growth of the manufacturing sector's output as a regressor instead of $\pi, E .^{35}$ Omitting the profit share raises the long-term effect of utilization and lowers the impact of the labor market indicator (a one percentage point increase in $u$ now raises the steady growth value of the annual accumulation rate by 1.56 to 2.45 percentage points). Incorporating $\hat{Y}$ lowers the long-term one-percentage-point impact of $u$ on $\hat{K}$ to 0.4 to 0.6 percentage points.

Table 3: Investment; Manufacturing; Fed capacity data, quarterly

\begin{tabular}{|c|c|c|c|c|c|c|}
\hline VARIABLES & $\begin{array}{c}\text { (1) } \\
\text { fed_manuf_khat }\end{array}$ & $\begin{array}{c}(2) \\
\text { fed_manuf_khat }\end{array}$ & $\begin{array}{c}\text { (3) } \\
\text { fed_manuf_khat }\end{array}$ & $\begin{array}{c}\text { (4) } \\
\text { fed_manuf_khat }\end{array}$ & $\begin{array}{c}(5) \\
\text { fed_manuf_khat }\end{array}$ & $\begin{array}{c}(6) \\
\text { fed_manuf_khat }\end{array}$ \\
\hline u_dev & $\begin{array}{c}0.0141 * * * \\
(3.93 \mathrm{e}-07)\end{array}$ & $\begin{array}{c}0.00788 * * * \\
(0.000483)\end{array}$ & $\begin{array}{c}0.0190 * * * \\
(0)\end{array}$ & $\begin{array}{c}0.0109 * * * \\
(6.26 \mathrm{e}-08)\end{array}$ & $\begin{array}{c}0.00845^{* * *} \\
(2.09 \mathrm{e}-06)\end{array}$ & $\begin{array}{c}0.00456 * * * \\
(0.000454)\end{array}$ \\
\hline E_dev & $\begin{array}{c}-0.00122 * * * \\
(1.63 \mathrm{e}-07)\end{array}$ & $\begin{array}{c}-0.000670 * * * \\
(0.000533)\end{array}$ & $\begin{array}{c}-0.00150 * * * \\
(0)\end{array}$ & $\begin{array}{c}-0.000828 * * * \\
(1.09 \mathrm{e}-05)\end{array}$ & & \\
\hline pi_dev & $\begin{array}{c}0.0138 * * * \\
(0.00214)\end{array}$ & $\begin{array}{c}0.00936 * * * \\
(0.00568)\end{array}$ & & & & \\
\hline $\begin{array}{l}\text { L.fed_- } \\
\text { manuf_khat }\end{array}$ & $\begin{array}{c}0.956^{* * *} \\
(0)\end{array}$ & $\begin{array}{c}1.671 * * * \\
(0)\end{array}$ & $\begin{array}{c}0.969 * * * \\
(0)\end{array}$ & $\begin{array}{c}1.695^{* * * *} \\
(0)\end{array}$ & $\begin{array}{c}0.941 * * * \\
(0)\end{array}$ & $\begin{array}{c}1.740 * * * \\
(0)\end{array}$ \\
\hline $\begin{array}{l}\text { L2.fed_- } \\
\text { manuf_khat }\end{array}$ & & $\begin{array}{c}-0.875^{* * *} \\
(0)\end{array}$ & & $\begin{array}{c}-0.891^{* * *} \\
(0)\end{array}$ & & $\begin{array}{c}-0.926^{* * *} \\
(0)\end{array}$ \\
\hline $\begin{array}{l}\text { L4.fed_- } \\
\text { manuf_khat }\end{array}$ & & $\begin{array}{l}0.170 * * * \\
(1.73 \mathrm{e}-07)\end{array}$ & & $\begin{array}{l}0.168 * * * \\
(3.57 \mathrm{e}-07)\end{array}$ & & $\begin{array}{l}0.141 * * * \\
(2.12 \mathrm{e}-05)\end{array}$ \\
\hline $\begin{array}{l}\text { y_manuf_ } \\
\text { khat }\end{array}$ & & & & & $\begin{array}{c}0.00690 * * * \\
(0.00465)\end{array}$ & $\begin{array}{c}0.00481^{* * * *} \\
(0.00556)\end{array}$ \\
\hline Constant & $\begin{array}{c}0.000387 * * \\
(0.0215)\end{array}$ & $\begin{array}{c}0.000313 * * \\
(0.0183)\end{array}$ & $\begin{array}{c}0.000257 \\
(0.123)\end{array}$ & $\begin{array}{c}0.000231^{*} \\
(0.0790)\end{array}$ & $\begin{array}{c}0.000480 * * * \\
(0.00672)\end{array}$ & $\begin{array}{c}0.000384 * * * \\
(0.00298)\end{array}$ \\
\hline Observations & 196 & 196 & 196 & 196 & 196 & 196 \\
\hline R-Squared & 0.960 & 0.977 & 0.958 & 0.976 & 0.950 & 0.975 \\
\hline Prob $>F$ & 0 & 0 & 0 & 0 & 0 & 0 \\
\hline$B G-L 1 P>\chi^{2}$ & 0 & 0.222 & 0 & 0.311 & 0 & 0.223 \\
\hline BG-L2 P > $\chi^{2}$ & 0 & 0.355 & 0 & 0.519 & 0 & 0.342 \\
\hline$B G-L 3 P>\chi^{2}$ & 0 & 0.361 & 0 & 0.634 & 0 & 0.446 \\
\hline BG-L4 P > $\chi^{2}$ & 0 & 0.501 & 0 & 0.589 & 0 & 0.202 \\
\hline
\end{tabular}

$$
\begin{gathered}
\mathrm{p} \text {-values in parentheses } \\
{ }_{* * *} \mathrm{p}<0.0 \mathrm{I},{ }^{* *} \mathrm{p}<0.05,{ }^{*} \mathrm{p}<0 . \mathrm{I}
\end{gathered}
$$

Annual data are less suitable for the partial adjustment described in equations (18), (28) and (35), but Table 4 presents estimates where the dependent variable is annual $\hat{K}$ using BEA capital stock data for the NFCB sector. Utilization in Table 4 is measured as NFCB

35 No quarterly deflator exists for this sector in the NIPA tables, so we use the price deflator for the NFCB sector. 
output divided by trend; profit shares are also from the NFCB sector. In addition to utilization, columns I-2 use as independent variables the deviations of the labor market indicator and profit share from their long term trend, and columns $3-4$ use NFCB output growth. The labor market indicator $E$ in columns $\mathrm{I}-2$ is the only variable which fails to be significant. The long-term effects on annual accumulation are very similar to estimates from the quarterly regressions based on Fed data: a one percentage point increase in utilization raises the steady growth annual accumulation rate by 0.8 to I.3 percentage points, but the error terms have serial correlation, even after incorporating additional lags of the dependent variable, and this could bias the coefficients in Table 4.

Table 4: Investment; Corporate Non Financial Business; BEA data, annual

\begin{tabular}{|c|c|c|c|c|}
\hline VARIABLES & $\begin{array}{c}(1) \\
\text { bea_corpnf_khat }\end{array}$ & $\begin{array}{c}(2) \\
\text { bea_corpnf_khat }\end{array}$ & $\begin{array}{c}\text { (3) } \\
\text { bea_corpnf_khat }\end{array}$ & $\begin{array}{c}(4) \\
\text { bea_corpnf_khat }\end{array}$ \\
\hline yy_u & $\begin{array}{l}0.166 * * * \\
(3.32 \mathrm{e}-07)\end{array}$ & $\begin{array}{l}0.146 * * * \\
(8.36 \mathrm{e}-06)\end{array}$ & $\begin{array}{c}0.253^{* * *} \\
(0)\end{array}$ & $\begin{array}{c}0.240 * * * \\
(0)\end{array}$ \\
\hline E_dev & $\begin{array}{c}-0.00102 \\
(0.631)\end{array}$ & $\begin{array}{c}-0.000322 \\
(0.877)\end{array}$ & & \\
\hline pi_dev & $\begin{array}{l}0.149 * * * \\
(8.62 \mathrm{e}-05)\end{array}$ & $\begin{array}{l}0.157 * * * \\
(3.30 \mathrm{e}-05)\end{array}$ & & \\
\hline $\begin{array}{l}\text { L.bea_corpnf_ } \\
\text { khat }\end{array}$ & $\begin{array}{c}0.808^{* * *} \\
(0)\end{array}$ & $\begin{array}{c}0.915^{* * *} \\
(0)\end{array}$ & $\begin{array}{c}0.790^{* * *} \\
(0)\end{array}$ & $\begin{array}{c}0.968^{* * * *} \\
(0)\end{array}$ \\
\hline $\begin{array}{l}\text { L2.bea_corpnf_ } \\
\text { khat }\end{array}$ & & $\begin{array}{c}-0.198^{* *} \\
(0.0373)\end{array}$ & & $\begin{array}{c}-0.239 * * * \\
(0.00837)\end{array}$ \\
\hline $\begin{array}{l}\text { L4.bea_corpnf_ } \\
\text { khat }\end{array}$ & & $\begin{array}{c}0.0992 \\
(0.147)\end{array}$ & & $\begin{array}{c}0.0224 \\
(0.706)\end{array}$ \\
\hline yhat & & & $\begin{array}{c}0.0587 * * * \\
(0.00137)\end{array}$ & $\begin{array}{c}0.0620 * * * \\
(0.000594)\end{array}$ \\
\hline Constant & $\begin{array}{c}0.00626^{* * *} \\
(0.00795)\end{array}$ & $\begin{array}{c}0.00604^{* *} \\
(0.0177)\end{array}$ & $\begin{array}{c}0.00422^{* *} \\
(0.0348)\end{array}$ & $\begin{array}{c}0.00534^{* *} \\
(0.0249)\end{array}$ \\
\hline Observations & 49 & 49 & 58 & 55 \\
\hline R-Squared & 0.831 & 0.839 & 0.829 & 0.843 \\
\hline Prob $>F$ & 0 & 0 & 0 & 0 \\
\hline BG-L1 P> $>\chi^{2}$ & 0.0103 & 0.0220 & 0.000170 & 0.000493 \\
\hline BG-L2 P> $\chi^{2}$ & 0.0252 & 0.0153 & 0.000780 & 0.00203 \\
\hline BG-L3 P> $>\chi^{2}$ & 0.0397 & 0.0106 & 0.000447 & 0.00193 \\
\hline BG-L4 P > $\chi^{2}$ & 0.0399 & 0.0242 & 0.00125 & 0.00405 \\
\hline
\end{tabular}

$\mathrm{p}$-values in parentheses

${ }^{* * *} \mathrm{p}<0.0 \mathrm{I},{ }^{* *} \mathrm{p}<0.05,{ }^{*} \mathrm{p}<0 . \mathrm{I}$ 
Overall, the estimated adjustment speed seems very low but with this caveat, the Robinsonian and Kaldorian specifications are consistent with the results, and the Kaldorian simulation in Figure 2 is based on an accumulation function with long-run effects that are in line with the regressions. The Kaleckian specification, by contrast, finds no support in the regressions: The estimated accumulation functions have a very low short-run sensitivity to changes in $u$ - thus satisfying the Keynesian stability condition for the short run - but the long-run sensitivity greatly exceeds any plausible value of the sensitivity of the long-run saving-capital ratio. ${ }^{36}$

\subsubsection{Comparisons}

Several recent papers have estimated simple dynamic systems in the post-Keynesian or neo-Marxian tradition. Using our notation in this paper, Barbosa-Filho and Taylor (2006) and Nikiforos and Foley (20II) estimate slightly extended versions of the following two equations, ${ }^{37}$

$$
\begin{aligned}
& \dot{u}=F(u, \pi), \\
& \dot{\pi}=G(u, \pi) .
\end{aligned}
$$

Both Barbosa-Filho/Taylor and Nikiforos/Foley find negative effects of utilization on the changes in utilization and profits $\left(F_{u}<0, G_{u}<0\right)$; the profit share has a positive effect on the change in utilization but a negative effect on changes in profits $\left(F_{\pi}>0, G_{\pi}<0\right)$.

The specification in equations (41) - (42) differs from ours in two important respects. First, there is no distinction between the utilization rate and the employment rate. From our perspective this is a weakness: There is no necessary connection between the two variables in the long run; their short-run movements are not perfectly synchronized but describe systematic clockwise cycles in $(e-u)$ space; their effects on firms' decisions are likely to be quite different. Second, there is no attempt to estimate a separate investment function, although in a Kaldorian context the dynamic equation for the utilization rate can be given a straightforward interpretation as a combination of the output and investment decisions.

The differences in specification - in particular the absence of a distinction between employment and utilization - make it difficult to compare the results to those in this paper. It should be noted, however, that with respect to the Robinsonian pricing hypothesis, the

36 All the long run sensitivities are partial: the increase in accumulation will have derived effects on the profit share (the equilibrium condition for the product market requires that $s \pi u=g+\delta$ ). Taking into account these derived effects would increase the long-run sensitivity of accumulation to changes in utilization.

37 The extensions involve additional lags, the inclusion of dummy variables and, in the case of Nikiforos and Foley, the estimation of the equations on separate subsamples delineated on the basis of the value of employment rate. 
two papers are in line with ours: The negative effect of utilization on the change in the profit share does not support a Robinsonian adjustment. ${ }^{38}$

\section{Conclusion}

Macroeconomic variables exhibit fluctuations around their long-term trends, and the simulations of the Kaldorian and Robinsonian models in this paper successfully reproduce some of the key patterns in the US data. Clearly, it is not a perfect fit. The models did not include any stochastic shocks and therefore do not capture the irregularity of the empirical cycles in terms of periodicity and amplitude. We also deliberately left out the public and foreign sectors in order to focus on the dynamics of a pure capitalist system; from an empirical perspective this is a serious omission. The equilibrium condition for the product market and thus the market clearing solution for the profit share in the Kaldorian model and the utilization rate in the Robinsonian model - are affected by the foreign and public sectors, and the behavior of these sectors may influence both short-run fluctuations and long-term trends in the data.

The absence in the theoretical model of the public and foreign sectors and of shortterm shocks to aggregate demand does not, however, invalidate the reasoning behind the behavioral equations. These equations summarize how signals from input and output markets affect firms' investment, pricing and output decisions, and as long as firms operate within a stable environment there is no reason for these behavioral equations to shift.

The latter condition may seem questionable, especially since the environment can be influenced by changes in the foreign and public sectors. As a result, firms' interpretation of the signals they receive may be affected and the behavioral functions may not be stable. Trends in international competition, for instance, can influence the desired markup and generate a shift in the Kaldorian growth function; changes in the policy regime may also lead to shifts in the behavioral equations. ${ }^{39}$ We have tried to address this concern by looking at the deviations of variables from their long-term trends. This, admittedly, is a crude and imperfect correction, but in the Kaldorian growth function, for instance, firms respond to the deviation of actual profit margins from the desired levels, and the trend may provide a proxy for the desired level.

The empirical evidence fails to support the Robinsonian and Kaleckian models. Our regressions reject Robinsonian specifications of changes in the profit share, and the estimated

38 In their estimation of a Goodwin model, Desai (1984) and Harvie (2000) use the employment rate rather than the utilization rate to explain distributional change. They find a negative effect of employment on the change in the profit share.

39 The dependence of behavioral equations on the policy regime is sometimes associated with the Lucas critique. Long before Lucas, however, it had been pointed out by Keynesians that a government commitment to countercyclical demand policies could have an immediate effect on instability through its effects on firms' expectations. 
investment functions violate the assumptions underlying the Kaleckian growth model. The Kaldorian model fares better. The estimation of the growth function gave plausible coefficients, and the stylized cyclical patterns could be reproduced using parameters that are in line with the estimates.

The econometric results should be regarded as preliminary. The Kaldorian growth equation performed well econometrically, but we are not aware of other econometric work on this relation. Our results therefore may not be robust, and the correlations could have other explanations. The accumulation function may be subject to more serious problems. Investment decisions are notoriously difficult to model. Pervasive uncertainty makes longterm investment subject to shifts in ranimal spirits, and our benchmark models paid attention to neither monetary policy nor the effects of broader changes in the financial environment. ${ }^{40}$ Biases arising from omitted variables and simultaneity problems may also affect the results. Our use of aggregate data, finally, can be questioned; firm-level data could provide a stronger test of the behavioral hypotheses. A more thorough empirical analysis to address these concerns is left for future research.

The theoretical model also needs to be extended. The omission of public and foreign sectors has already been commented on. Another problem is the benchmark models' neglect of financial stocks and the influence of financial variables on both household consumption and firms' investment decisions. Some work has been done in this direction but much more is needed..$^{4 \mathrm{r}}$ First and foremost, however, there is a need for theoretically informed, empirical work.

\section{References}

Auerbach, P., Skott, P. (1988): Concentration, competition and distribution, in: International Review of Applied Economics, 2(I), 42-6I.

Barbosa-Filho, N.H., Taylor, L. (2006): Distributive and Demand Cycles in the US Economy - A Structuralist Goodwin Model, in: Metroeconomica, 57(3), 389-4II.

Bhaduri, A. (2003): Alternative approaches to endogenous growth, mimeo.

Blecker, R. (20I0): Open economy models of distribution and growth, paper presented at the Eastern Economic Association Meetings, February 2010.

Crotty, J. (2005): The neoliberal paradox: The impact of destructive product market competition and 'modern f financial markets on nonfinancial corporation performance in the neoliberal era, in: Epstein, G.A. (ed.), Financialization and the World Economy, Northampton, MA: Edward Elgar.

40 A large literature discusses the sfinancialization (2005), Epstein (2005), Krippner (2005), Palley (2007), Stockhammer (2004).

4I A recent post-Keynesian literature has focused on stock-flow consistent modeling (e.g. Godley/ Lavoie 2006 and Dos Santos/Zezza 2008). This is not a new idea, however; Skott (1989a), for instance, presents a stock-flow consistent version of the basic Kaldorian model. Skott/Ryoo (2008) consider the long-run implications of changes in financial behavior, and Ryoo (2010) analyzes a stock-flow consistent Kaldorian model with long waves of Minskian financial instability. 
Dallery, T., van Treeck, T. (20II): Conflicting claims and equilibrium adjustment processes in a stock-flow consistent macro model, in: Review of Political Economy, 23(2), I89-2II.

Desai, M. (1984): An econometric model of the share of wages in national income, in: Goodwin, R.M, Krüger, M., Vercelli, A. (eds), Nonlinear Models of Fluctuating Growth, Berlin: Springer.

Dos Santos, C.H., Zezza, G. (2008): A simplified, benchmark, stock-flow consistent postKeynesian growth model, in: Metroeconomica, 59(3), 44I-478.

Dutt, A.K. (1984): Stagnation, income distribution and monopoly power, in: Cambridge Journal of Economics, 8(I), 25-40.

Dutt, A.K. (1995): Internal finance and monopoly power in capitalist economies: a reformulation of Steindl's growth model, in: Metroeconomica, 46(I), I6-34.

Dutt, A.K. (1997): Equilibrium, path dependence and hysteresis in post-Keynesian models, in: Arestis, P., Palma, G., Sawyer, M. (eds.), Capital Controversy, Post-Keynesian Economics and the History of Economic Thought: Essays in Honour of Geoff Harcourt, London: Routledge.

Dutt, A.K. (2006): Aggregate demand, aggregate supply and economic growth, in: International Review of Applied Economics, 20(3), 319-336.

Epstein, G.A. (2005): Introduction, in: Epstein, G.A. (ed.), Financialization and the World Economy, Northampton, MA: Edward Elgar.

Flaschel, P., Krolzig, H.M. (2006): Wage-price Phillips Curves and macroeconomic stability, basic structural form, estimation and analysis, in: Chiarella, C., Flaschel, P., Franke, R., Semmler, W. (eds.), Quantitative and Empirical Analysis of Nonlinear Dynamic Macromodels - Contributions to Economic Analysis, Amsterdam: Elsevier.

Flaschel, P., Skott, P. (2006): Steindlian models of growth and stagnation, in: Metroeconomica, $57(3), 303-338$.

Godley, W., Lavoie, M. (2006): Monetary Economics: An Integrated Approach to Credit, Money, Income, Production and Wealth, Basingstoke: Macmillan.

Harvie, D. (2000): Testing Goodwin: growth cycles in ten OECD countries, in: Cambridge Journal of Economics, 24(3), 349-376.

Hein, E. (2007): Interest rate, debt, distribution and capital accumulation in a post-Kaleckian model, in:. Metroeconomica, 58(2), 310-339.

Hein, E., Lavoie, M., van Treeck, T. (20I2): Some instability puzzles in Kaleckian models of growth and distribution: A critical survey, in: Metroeconomica, 63(I), I39-I69.

Kalecki, M. (1943): Political aspects of full employment, reprinted in Kalecki, M., Selected Essays on the Dynamics of the Capitalist Economy, Cambridge: Cambridge University Press, I97I.

Krippner, G.R. (2005): The financialization of the American economy, in: Socio-Economic Review, 3(2), 173-208.

Kurz, H. (1986): Normal positions and capital utilization, in: Political Economy, 2(I), 37-54.

Lavoie, M. (1995): The Kaleckian model of growth and distribution and its neo-Ricardian and neo-Marxian critiques, in: Cambridge Journal of Economics, I9(6), 789-818.

Manning, A. (2003): Monopsony in Motion, Princeton: Princeton University Press. 
Marglin, S.A. (1984): Growth, distribution, and inflation: a centennial synthesis, in: Cambridge Journal of Economics, 78(2), II5-I44.

Marglin, S.A., Bhaduri, A. (1990): Profit Squeeze and Keynesian Theory, in: Marglin, S., Schor, J. (eds.), The Golden Age of Capitalism - Reinterpreting the Postwar Experience, Oxford: Clarendon.

Mohun, S., Veneziani, R. (2008): Goodwin cycles and the US economy, 1948 - 2004, in: Flaschel, P. Landesmann, M. (eds.), Mathematical Economics and the Dynamics of Capitalism Goodwin's Legacy Continued, London and New York: Routledge.

Nakatani, T., Skott, P. (2007): Japanese growth and stagnation, in: Structural Change and Economic Dynamics, I8(3), 306-332.

Nikiforos, M., Foley, D.K. (20I2): Distribution and capacity utilization: conceptual issues and empirical evidence, in: Metroeconomica, 63(I), 200-229.

Palley, T.I. (2007): Financialization: What it is and why it matters, Levy Economics Institute Working Paper No. 525 .

Robinson, J. (1956): The Accumulation of Capital, London, Basingstoke: Macmillan.

Robinson, J. (1962): Essays on the Theory of Economic Growth, London, Basingstoke: Macmillan.

Rowthorn, B. (198I): Demand, real wages and economic growth, in: Thames Papers in Political Economy, Autumn.

Ryoo, S. (2010): Long waves and short cycles in a model of endogenous financial fragility, in: Journal of Economic Behavior and Organization, 74(3), 163-186.

Ryoo, S., Skott, P. (2008): Financialization in Kaleckian economies with and without labor constraints, in: Intervention. European Journal of Economics and Economic Policies, 5(2), 363-392.

Setterfield, M., Leblond, K. (2003): The Phillips Curve and US macroeconomic performance during the I990s, in:International Review of Applied Economics, I7(4), 36I-76.

Skott, P. (1989a): Conflict and Effective Demand in Economic Growth, Cambridge: Cambridge University Press.

Skott, P. (1989b): Effective demand, class struggle and cyclical growth, in: International Economic Review, 30(I), 23I-247.

Skott, P. (I999): Wage formation and the (non-)existence of the NAIRU, in: Economic Issues, 4(I), 77-92.

Skott, P. (2005a): Fairness as a source of hysteresis in employment and relative wages, in: Journal of Economic Behavior and Organization, 57(3), 305-331.

Skott, P. (2005b): Equilibrium, stability and economic growth, in Gibson, B. (ed.), Joan Robinson's Economics: A Centennial Celebration, Northampton, MA: Edward Elgar.

Skott, P. (20IO): Growth, instability and cycles: Harrodian and Kaleckian models of accumulation in income distribution, in: Setterfield, M. (ed.), Handbook of Alternative Theories of Economic Growth, Northampton, MA: Edward Elgar.

Skott, P. (20I2): Theoretical and empirical shortcomings of the Kaleckian investment function, in: Metroeconomica, I09-I38.

Skott, P., Ryoo, S. (2008): Macroeconomic implications of financialization, in: Cambridge Journal of Economics, 32(6), 827-862. 
Steindl, J. (1952): Maturity and Stagnation in American Capitalism, Oxford: Blackwell.

Stockhammer, E. (2004): Financialisation and the slowdown of accumulation, in: Cambridge Journal of Economics, 28(5), 719-74I.

Zipperer, B., Skott, P. (20II): Cyclical patterns of employment, utilization and profitability, in: Journal of Post Keynesian Economics, 44(I), 25-58. 